\title{
RETRACTED ARTICLE: Some Remarks on Univalent Harmonic Mappings
}

\author{
Deepali Khurana $^{1} \cdot$ Sushma Gupta $^{1}$. \\ Sukhjit Singh ${ }^{1}$
}

This article has been retracted by the Editor-in-Chief in agreement with the authors because it contains technical errors in the proofs of Conjecture 1.2 and Conjecture 1.3. The online version of this article contains the full text of the retracted article as electronic supplementary material.

Electronic supplementary material The online version of this article (doi:10.1007/s40840-016-0367-6) contains supplementary material, which is available to authorized users.

$\varangle \quad$ Deepali Khurana

deepali.02.08.88@gmail.com

1 Department of Mathematics, Sant Longowal Institute of Engineering and Technology, Longowal, Punjab 148106, India 